\title{
Influence of the Silicon- and Element-Organic Compounds on the Process of Biochemical Oxidation in the Organic Contaminations
}

\author{
Vilen M. Kantere, Tatyana G. Mukhamedzhanova, Ludmila A. Tchurmasova, \\ Olga G. Ryzhova, Svetlana V. Zhukova \\ Moscow State University of Food Production, Moscow, Russia \\ Email: djiolta@mail.ru
}

Received November 7, 2011; revised December 27, 2011; accepted January 5, 2012

\begin{abstract}
One of the methods used in practice for the purification of wastewater from vegetable-processing enterprises is biological method of aerobic purification. With the aim to increase air-tank capacity used in traditional systems of biochemical purification of wastewater, different ways effecting to the process of vital activity of microorganisms of active sludge are applied. On the one hand, using the compositions of different salts and complex organic biogenous supplements prevents from the accumulation of some anions in the amounts exceeding the limited concentration, on the other handallows different groups of microorganisms to choose biogenous elements, which they assimilate easily and fully. It is known, that compounds of silicon and germanium can cause stimulating effects [1] to the organisms of active sludge. The goal of present studies is the intensification of biological processes of oxidation of organic contamination in wastewater by new bio-degradable chemical compounds or compositions on their basis, and by bio-sorbents.
\end{abstract}

Keywords: Biochemical Oxidation; Contamination in Wastewater; Biological Method of Aerobic Purification

\section{Introduction}

Experimental studies of biological purification of the average industrial wastewater from food industry enterprises (COD $820 \mathrm{mg} \mathrm{O}_{2} / \mathrm{dm}^{3}$ ) were performed in laboratory conditions of MSU FP. Bio-stimulators were as follows: hexamethylcyclotrisilazane (HMCTS), tetraethoxisilane (TEOS), germatranol (G); shungit-natural mineral on the basis of fulerene, the deposits of which are at Karelia, was used as an sorbent.

Active sludge used in the experiments was taken from industrial air tanks. Micro flora of active sludge grown for $24 \mathrm{~h}$ at $37^{\circ} \mathrm{C}$ on nutrient medium of the following composition: meat-peptone agar- $1 \%$; $\mathrm{NaCl}-0.5 \%$, $\mathrm{NH}_{4} \mathrm{H}_{2} \mathrm{PO}_{4}-0.1 \% ; \mathrm{K}_{2} \mathrm{HPO}_{4}-0.1 \%$; $\mathrm{pH}-7.2-7.4$ was used as test organisms. To access biological activity of bio-activators under study, the method of the determination of fermentative activity (dehydrogenase) and microbiological activity (by the intensity of water-dissolved oxygen consumption by microorganisms in active sludge) [2,3].

Content of microorganisms in culture liquid was standardized and introduced into each sample in the definite amount. Each sample contained the components under study in different concentration. Industrial wastewater without supplements was used as control.

\section{Results and Discussion}

With the aim to choose the components stimulating the process of biochemical degradation of organic contamination, we have studies the influence of these components on dehydrogenase activity $(0.015 \mathrm{mg} / \mathrm{l})$.

Data obtained during the experiments showed that maximal acceleration of time of decolorization of methylene blue in the experimental sample, as compared to control, was observed at the introduction of germatranol, deviation was $12.2 \%$. At the introduction of hexamethylcyclotrisilazane and tetraethoxisilane it was $8.8 \%$ and $6.0 \%$, correspondingly.

Taking into account, that germatranol is rather expensive component; we have studied on the next stage the influence of the compositions on the basis of hexamethylcyclotrisilazane.

Results of the experiments are presented in Table 1.

Basing on the experimental data of the study of the influence of active sludge of two compositions on dehydrogenase activity, one can conclude that the most efficient influence had the composition consisting of $70 \%$ of 
Table 1. Influence of the compositions under study on dehydrogenase activity.

\begin{tabular}{|c|c|c|c|c|c|}
\hline \multirow{2}{*}{$\begin{array}{l}\text { Total concentration } \\
\text { of composition, } \mathrm{mg} / \mathrm{l}\end{array}$} & \multirow{2}{*}{$\begin{array}{l}\text { Weight ratio of HMCTS } \\
\text { to the components }\end{array}$} & \multicolumn{2}{|c|}{ Concentration of substances, $\mathrm{mg} / \mathrm{l}$} & \multicolumn{2}{|c|}{$\begin{array}{l}\text { Deviation from control on dehydrogenase activity, } \\
\% \text { of compositions }\end{array}$} \\
\hline & & HMCTS & Component & TEOS & G \\
\hline \multirow{9}{*}{0.015} & $90: 10$ & 0.0135 & 0.015 & 12.9 & 12.8 \\
\hline & $80: 20$ & 0.0120 & 0.0030 & 10.1 & 15.9 \\
\hline & $70: 30$ & 0.0105 & 0.0045 & 8.8 & 21.0 \\
\hline & $60: 40$ & 0.0090 & 0.0060 & 6.5 & 20.0 \\
\hline & $50: 50$ & 0.0075 & 0.0075 & 6.0 & 17.8 \\
\hline & $40: 60$ & 0.0060 & 0.0090 & 5.0 & 16.5 \\
\hline & $30: 70$ & 0.0040 & 0.0110 & 4.1 & 9.9 \\
\hline & $20: 80$ & 0.0030 & 0.0120 & 3.9 & 10.1 \\
\hline & $10: 90$ & 0.0015 & 0.0135 & 3.0 & 9.6 \\
\hline
\end{tabular}

hexamethylcyclotrisilazane and $30 \%$ of germatranol in total concentration of $0.015 \mathrm{mg} / \mathrm{l}$.

In this case deviation from control is $21 \%$. This composition maximally increases the fermentative activity of sludge.

After the increase or reduction of germatranol part in the composition, gradual reduction of the activity takes place. Obviously, it can be explained by biological activeity of germatranol as well as of HMCTS, but at their different weight ratios the overlapping of the activities (synergism) or antagonism takes place.

Experiments performed with the reduction of total concentration of the components to $0.0075 \mathrm{mg} / \mathrm{l}$ showed the maximal deviation from control at 50:50 ratio of the same components. However, it was only $10.5 \%$. The increase of total concentration of these components to $0.030 \% \mathrm{mg} / \mathrm{l}$ shows maximal deviation from control $15.0 \%$ at 70:30 ratio of the components.

Results of the study of the influence of the compositions on the basis of HMCTS on microbiological activity of sludge are presented in Table 2.

On the basis of the experimental date we can make the following conclusion: the most efficient influence on the active consumption of water dissolved oxygen by microorganisms of active sludge was observed in the composition with germatranol, consisting of $60 \%$ of hexamethylcyclotrisilazane and 40\%-germatranol. In this case microbiological activity of sludge is of maximal value $(+22.2 \%)$, after the increase or reduction of the part of germatranol, gradual reduction of the activity takes place. Therefore, by using express-methods we have obtained active composition on the basis of hexamethylcyclotrisilazane and germatranol, weight interval of the composition can be in the range of 70:30 - 60:40 with total concentration- $0.0150 \mathrm{mg} / \mathrm{l}$.

Literature date show that different adsorbents increase the efficiency of wastewater purification [4].

It was studied the possibility to use adsorbent-shungite-for the purification of wastewater, containing phenol
Table 2. Influence of compositions on microbiological activity of active sludge.

\begin{tabular}{ccc}
\hline \multirow{2}{*}{$\begin{array}{c}\text { Weight ratio of } \\
\text { HMCTS to the } \\
\text { component }\end{array}$} & $\begin{array}{c}\text { Deviation from control, \% by dissolved oxygen } \\
\text { consumption of compositions }\end{array}$ \\
\cline { 2 - 3 } & With TEOS & With G \\
\hline $90: 10$ & 19.3 & 17.8 \\
$80: 20$ & 17.0 & 17.1 \\
$70: 30$ & 15.2 & 18.9 \\
$60: 40$ & 14.0 & 22.2 \\
$50: 50$ & 12.1 & 19.8 \\
$40: 60$ & 9.4 & 18.7 \\
$30: 70$ & 6.6 & 16.5 \\
$20: 80$ & 5.7 & 17.0 \\
$10: 90$ & 4.8 & 15.3 \\
\hline
\end{tabular}

(total concentration of compositions- $0.015 \mathrm{mg} / \mathrm{l}$ ).

with toxic concentration $0.20 \mathrm{mg} / \mathrm{l}$ in air-tank for 20 days. Introduction of $0.5 \mathrm{mg} / \mathrm{l}$ of shungit into air-tank provides the reduction of toxic effect of phenol to micro flora of active sludge. Efficacy of the purification by BOD in the experimental air-tank during 20 days decreased only from $95 \%$ (control) to $92 \%$. Without the addition of shungit the efficacy of purification decreased only from $95 \%$ to $89 \%$ during 3 days and then it decreased to $62 \%$.

Obviously, the increase of the efficacy of purification is connected with adsorption of organic contaminants in pores of adsorbent. Micro flora of active sludge in control air-tank and in the experimental one (with the addition of shungit) was presented by large zoogloea. Also small, light zoogloea were available, which present young colonies of bacteria. Filamentous bacteria was presented in active sludge by small amounts. Micro fauna was well developed (mass development of Hypotricha and Peritricha was observed). Purified water does not contain entero viruses and bacteria of Colibacillus group. Therefore, results of the studies show the intensification of biological processes of wastewater of food industry en- 
terprises at the expense of the introduction of the compositions on the basis of silicon-organic compounds. The addition of shungit adsorbent provides stable bio-oxidation processes of organic substances by heterotrophic microorganisms.

\section{REFERENCES}

[1] M. G. Voronkov, G. I. Zelchan and E. Y. Lukevits, "Silicon and Life,” Zinante, Riga, 1978, p. 64.
[2] Yu. Luriye, "Analytical Chemistry of Industrial Wastewater,” Chemistry, St. Petersburg, 1984, p. 448.

[3] B. N. Repin, "Methods of Biological Purification of Wastewater," Nauka, Moscow, 1986

[4] E. N. Nirullina, A. S. Sirotkin, et al., "Intensification of Biological Oxidation of Organic Contaminants in the Biosorption Systems of Sewage Treatment Biotechnology,” Biotechnology, Moscow, 2002, pp. 61-69. 